\title{
Feeding difficulties in disabled children leads to malnutrition: experience in an Indian slum
}

\author{
Aisha K. Yousafzai ${ }^{\star}$, Suzanne Filteau and Sheila Wirz \\ Centre for International Child Health, Institute of Child Health, University College London, 30 Guilford Street, \\ London WC1N 1EH, UK
}

(Received 16 October 2002 - Revised 30 July 2003 - Accepted 30 July 2003)

\begin{abstract}
The aim of the present study was to explore the nature, extent and probable causes of nutritional deficiencies among children with disabilities living in Dharavi, a slum in Mumbai, India. A cross-sectional study was conducted to investigate whether the nutritional status of children with disabilities, aged $2-6$ years $(n$ 141), was worse than that of non-disabled sibling controls $(n 122)$ and neighbour controls (n 162). Data on food patterns, anthropometry, micronutrient status and feeding difficulties reported by parents were collected. The mean weight for age of the children with disabilities ( -2.44 (SD 1.39) $Z$ scores; $n$ 120) was significantly lower $(P<0.05)$ compared with the sibling ( -1.70 (SD 1.20) $Z$ scores; $n$ 109) and neighbour ( -1.83 (SD 1.290) $Z$ scores; $n$ 162) control groups. The children with disabilities had significantly lower $(P<0 \cdot 05)$ mean haemoglobin levels (92 (SD 23) g/l; $n$ 134) compared with siblings (102 (SD 18) g/l; $n$ 103 ) and neighbours (99 (SD 18) g/l; $n$ 153). Relative risk (RR) analysis indicated that the disabled children with feeding difficulties were significantly more likely $(P<0.05)$ to be malnourished, by the indicator of weight for age (RR $1.1 ; 95 \%$ CI $1.08,1 \cdot 20)$ compared with the disabled children without a feeding difficulty. They were also significantly more likely to be malnourished using the indicators of height for age (RR 1.3; $95 \%$ CI 1.19, 1.43) and weight for height (RR 2.4; $95 \%$ CI 1.78, 3.23) compared with the disabled children without a feeding difficulty. Feeding difficulties were identified as a risk factor for vulnerability to inadequate nutritional status among children with disabilities.
\end{abstract}

Disability: Feeding difficulties: Indian slum community

A global figure of 335 million individuals with moderate and severe disabilities, of whom $70 \%$ are living in the developing world, has been estimated based on the UN population statistics for 2000 (Helander, 1998). Common causes of disability include congenital disturbances, communicable diseases, non-communicable diseases, functional psychiatric disturbances, substance abuse, trauma and malnutrition (Helander, 1998), some of which are likely to be higher in developing countries. In India, the prevalence of disability is estimated at 35 million individuals, of whom 15 million are children (Coleridge, 1993). Those with disabilities have a range of rehabilitation requirements that at present remain challenging to provide effectively in developing countries. Helander (1998) estimates that only $3 \%$ of rehabilitation needs are formally met; however, it is widely acknowledged that at the family level rehabilitation is both an on-going and spontaneous process. Many issues are being addressed by community-based projects and through the concept of inclusion in mainstream activities to reduce marginalisation of this population (Turmusani et al. 2002). Despite the progress made, there remains a growing awareness of the disparities in the health, education and nutritional status between children with and without disabilities.

It is recognised that children with disabilities can have a poorer nutritional status than their non-disabled peers (Thomas et al. 1989; American Dietetic Association, 1992). Nutritional deficits and growth disorders in children with disabilities have been reported by a number of investigators (Suzuki et al. 1991; Thommessen et al. 1991; Stallings et al. 1993; Willig et al. 1993). One identified factor that contributes to undernutrition and poor growth is feeding difficulties (Thommessen et al. 1991), which is particularly prevalent in children with cerebral palsy. Data from the UK suggest that feeding difficulties affect between 40 and $90 \%$ of children with cerebral palsy (Reilly \& Skuse, 1994; Trier \& Thomas, 1998). Feeding difficulties can be a cause of anxiety among the carers of children with disabilities (Reilly \& Skuse, 1992) and the consequent undernutrition is conducive to the sub-optimal health of the child.

Additional problems experienced by children with disabilities that can influence nutritional status include constipation, gastro-oesophageal reflux (Staiano et al. 1991, 
1994), poor health status (Reddihough et al. 2001; Fung et al. 2002), and respiratory infections (Shaw, 1996). Other problems are sedentary lifestyles and over-eating among adolescents with mental impairment (Suzuki et al. 1991), behavioural problems that compound the feeding problems (Richardson, 1988), and poor nutritional or feeding knowledge among the carers of disabled children (Verral et al. 2000). Undernutrition for children with disabilities can exacerbate the disability; for example, a weakened immune system can potentially delay the healing of pressure sores in children who have a physical impairment (Sullivan \& Rosenbloom, 1996). While the present study has addressed many rehabilitation issues, the identification and management of nutritional problems remains less well understood for children with disabilities (Sullivan \& Rosenbloom, 1996).

In developing countries the identification and management of nutritional problems among children with disabilities is further complicated by widespread malnutrition among the general population. Community-based crosssectional surveys have identified the nutritional status among children with disability as significantly poorer than non-disabled children in the Philippines (Socrates et al. 2000) and Nigeria (Tompsett et al. 1999). The major nutritional deficit identified among children with disability in higher-income countries has been low energy intake (Stallings et al. 1996; Sullivan et al. 2002). The quality of the diet in low-income communities, with consequent micronutrient deficiencies, may potentially further compromise the nutritional wellbeing of children with disabilities.

Many anecdotal comments about the neglect and poor nutritional status of the child with disability can be read, but few studies have explored this issue. A qualitative study conducted in an Indian slum explored the families' experiences of feeding problems in a resource-poor community (Yousafzai et al. 2003b). The provision of an adequate amount of food was difficult within all of the households (irrespective of disability) and there were some cases of preferential treatment towards those who worked outside of the home or who went to school, which may affect children with disabilities as they grow older. However, families were concerned about the eating habits of the disabled child and wanted information on managing feeding problems. Food was commonly described as vital for the child with disabilities in order for him or her to gain strength and 'get better' or in contrast, that the process of eating was difficult and painful if the child had a disability and parents felt improved feeding would take place once the child was 'stronger'. Families provided the same food for the disabled and non-disabled children, but often described the child with disabilities as having a poorer appetite. A lack of time for adequate feeding care was a barrier experienced by many mothers of children with feeding problems.

The present cross-sectional study was undertaken as a follow-up to the described qualitative study (Yousafzai et al. 2003b). Given the circumstances of poverty leading to difficulties in providing adequate quantities of food within households and the expected malnutrition in the general population, the null hypothesis of the present study was that the nutritional status of children with disabilities living in an Indian slum was not different from that of children without disability. The aim was to compare the nutritional status of disabled children with their nondisabled siblings and neighbours.

\section{Methods}

A cross-sectional survey of the nutritional status of children with disabilities (aged 2-6 years) in the Dharavi slum, Mumbai was conducted between January and June 1999. Dharavi covers an area of approximately $4.5 \mathrm{~km}^{2}$. The 1981 census stated that the population of Dharavi was 600000 with a growth rate prediction of $8.3 \%$ year (Crean et al. 1987). Due to the lack of information of addresses, convenience sampling was used for the identification of children with disabilities that later evolved through a snowballing effect. Two control groups were identified; a non-disabled sibling nearest in age and a non-disabled neighbour of the same sex and age within 6 months residing in the same nagar (neighbourhood) of Dharavi and without disability in the household. The sibling child was included in order to determine if other children in families with a disabled child are nutritionally disadvantaged.

The sample-size calculations were based on anthropometric and vitamin A data from India (Ramakrishnan et al. 1995; Bhandari et al. 1997) and on an estimated anaemia prevalence of $40 \%$ in slum children under 5 years. In order to show a difference at $5 \%$ significance and $80 \%$ power, of $0.3 \mathrm{SD}$ units in weight for age (wt/ age) $Z$ score, 150 children were required per group. The number was calculated to be sufficient to detect differences of $20 \%$ in the prevalence of anaemia and in serum vitamin A concentrations between the disabled cases and the two control groups. The survey identified 141 children with disabilities, but this made minimal difference to the power size.

\section{Identification of disability}

Children with disabilities were identified using the 'Ten Questions Screen' (Zamen et al. 1990). The screen was developed for the identification of major areas of disability in children aged 2-9 years. The screen, which has been validated in Bangladesh, Pakistan and Jamaica, serves as a low-cost and rapid means of identifying moderate to severe disabilities in diverse cultural settings, particularly in areas with few disability services (Durkin et al. 1994, 1995). The screen was administered in the local language (Hindi).

\section{Socio-economic status}

A structured questionnaire was developed for obtaining information about family background, care of children, literacy of carers, employment status and housing status. The data provided descriptive information on the study population and allowed the investigators to determine whether there were any significant differences between the case and control families that may have an effect 
on the nutritional status or feeding practices. The questionnaire format was finalised after the pilot study was conducted (Pai et al. 2001).

\section{Food patterns}

The food-frequency method was selected because such a method could incorporate the regional differences of food habits in India (Singhal et al. 1998), which was particularly important given that the population of a slum comprises immigrants from many states. The food-frequency method would reveal sufficient information to indicate the typical foods eaten regularly and if there were any significant variations among children. The food items were selected after a review of the pilot study (Pai et al. 2001) and discussions with local key informants. An inexhaustible food list was decided against because the purpose was not to estimate an actual level of nutrient intake. Parts of the list were open ended; for example, specific fruits were not listed, which was justified because of the expected limited accessibility of a variety of foods in an extremely deprived area. At the time of data collection, a standardised food-frequency list could not be found for use in an Indian population.

\section{Anthropometry}

Anthropometric measurements were carried out using standard protocols (United Nations, 1986). Weight was measured to the nearest $0.1 \mathrm{~kg}$ on standard electronic scales. If a child was unable to stand due to their age or type of impairment, they were weighed together with a carer and then the carer's weight was deducted from the value of the combined weight. Length was measured to the nearest $5 \mathrm{~mm}$ using a measures mat (Starters, Norwich, UK) for all children under 2 years of age and for older children unable to stand who were less than $0.92 \mathrm{~m}$ in length. Height was measured to the nearest $1 \mathrm{~mm}$ using a stadiometer (Leicester Portable Measure; CMS Weighing Equipment Ltd., UK). The researcher A. Y. took all the measurements.

The authors are aware that the height measurements for some of the subjects with physical impairments, for example those with kyphosis, were not accurate. Alternative long-bone measures were also taken of all children to predict height from linear regression analysis (Yousafzai et al. 2003a). Arm-span measurements were taken from the tip of the middle finger of one arm to the tip of the middle finger of the other arm with the arms outstretched at right angles to the body. Arm-length measurements were taken from the tip of the humerus bone to the tip of the middle finger of the left arm. Tibia length was measured from the knee joint to the ankle joint.

Mid-upper arm circumference (MUAC) was recorded to the nearest $1 \mathrm{~mm}$. Triceps skinfold and sub-scapular skinfold thicknesses were recorded to the nearest $0.1 \mathrm{~mm}$ using standard callipers (Holtain Skinfold Callipers; CMS Weighing Equipment Ltd, London, UK). The authors are aware of the difficulties in obtaining accurate skinfold measurements from either emaciated or obese children (Harris et al. 1984).

The age of the child could be given within 6 months by most carers. When a carer had difficulty recalling the age of the child, the times of local events and births of neighbourhood children were discussed to determine an approximate age and a note was made in the data-entry book of any such difficulties.

\section{Micronutrients and acute-phase proteins}

Haemoglobin was measured as an indicator of anaemia (cut-off below $110 \mathrm{~g} / \mathrm{l}$; World Health Organization (WHO, 1992) criteria) using the HemoCue (HemoCue Ltd, Sheffield, UK) and finger-prick blood samples. There was a $92 \%$ compliance rate for taking haemoglobin levels from the study population. The haemoglobin data were not validated against haemoglobin in the venous blood drawn. A. Y. took all haemoglobin measurements. In addition, a $5 \mathrm{ml}$ venous blood sample was taken in order to measure serum retinol (vitamin A), serum 25-hydroxyvitamin D (vitamin D), serum ferritin, and the acute-phase proteins, C-reactive protein (CRP) and $\alpha$-antichymotrypsin. There was $38 \%$ compliance for venous blood collection among the study population. Venous blood was taken by a trusted local doctor.

Ferritin was measured by a sandwich ELISA using both rabbit anti-ferritin antibody and peroxidase-conjugated antibody to ferritin from Dako (Cambridge, UK) and ferritin standards ranging from 0.63 to $20.00 \mu \mathrm{g} / \mathrm{l}$ (Beesley et al. 2000). Ferritin levels below $10 \mu \mathrm{g} / \mathrm{l}$ were taken as indicative of Fe-deficiency anaemia (Tietz, 1995). CRP was measured by a sandwich ELISA using both capture and horseradish peroxidase-conjugated antibodies to CRP from Dako (Cambridge, UK) and a CRP standard from Behring Diagnostics (Milton Keynes, UK) (Filteau et al. 1999). $\alpha$-Antichymotrypsin was measured using a turbidimetry assay on a Cobas Fara centrifugal analyser (Roche, Milton Keynes, UK), with standards (Dako) ranging from 0.05 to $1.24 \mathrm{~g} / \mathrm{l}$ (Beesley et al. 2000)

Vitamin A was measured by an HPLC assay (Filteau et al. 1995). The internal standard used was all trans-retinyl acetate and the standards used were all trans-retinol (Sigma, UK). The international vitamin A cut-off point for deficiency is taken as $0.7 \mu \mathrm{M}$. Vitamin D was analysed by radioimmunoassay ${ }^{125}$ I RIA Kit; DiaSorin, Stillwater MN, USA). Vitamin D deficiency in children was taken as less than $30 \mathrm{~nm}$ (Lawson et al. 1999).

\section{Feeding difficulties}

A structured schedule was developed to investigate the presence of feeding difficulties that may influence the nutritional status. All parents of children with a disability ( $n$ 141) were asked the following questions: (1) Does your child have difficulties in chewing?; (2) Does your child vomit at mealtimes?; (3) Does your child need help with feeding? The response categories to each of the above questions were: 'A lot of difficulty', 'Sometimes' or 'Never'. Based on the responses, the children with disabilities were categorised as either having a feeding difficulty, or having no or minor feeding difficulty. The schedule was administered in the local language.

Of the families with a disabled child, seventy-eight $(55 \%)$ were followed up 3 months after the initial 
feeding-difficulties questionnaire for further interviews regarding feeding practices. Data were collected on as many families and children that could be located because some had migrated to other areas, returned to their native place or were unavailable for follow-up.

\section{Data analysis}

Data were double-entered into Epi-Info software (version 6.04c; CDC, USA) and wt/age, height for age (ht/age) and weight for height (wt/ht) data were calculated using Epi-Nut software (version 2.0; CDC, USA), which uses the National Center for Health Statistics reference data (CDC, USA). These reference data are considered suitable for populations of young children from the developing world (Kow et al. 1991). Statistical analysis was completed on the statistical package for social sciences software (SPSS, version 8.0; Chicago, IL, USA).

Actual height measurements could not be used for $21 \%$ ( $n$ 29) of the children with disabilities. Instead, derived height predicted from arm-span ( $n$ 9), arm length $(n 8)$ and tibia length ( $n$ 12) were used during the analysis (Yousafzai et al. 2003a).

The three groups of children were compared by ANOVA followed by Duncan's multiple-range tests or, where appropriate, the Kruskal-Wallis one-way non-parametric ANOVA. The children with disabilities were taken as a cohort group and the relative risks for malnutrition were also calculated within the group. Pearson's correlation coefficient test or, where appropriate, the Spearman's rank correlation were used to look at correlations between different outcome measures. The distribution data for micronutrients and acute-phase proteins were checked and log-transformed if appropriate.

\section{Ethical considerations}

The ethical committee of Great Ormond Street Hospital in the UK approved the study and permission was granted from the local urban health centre in Dharavi for fieldwork to proceed. The study was explained to all families invited to participate and informed verbal consent was taken. All children received a course of vitamin $\mathrm{A}$, vitamin $\mathrm{D}, \mathrm{Fe}$ and folate supplements. Confidentiality was adhered to in all stages of data collection and data management.

\section{Results}

A total of 425 children were recruited to the study (Table 1). The classification of children with disabilities was based on the results of the 'Ten Questions Screen' (Zamen et al. 1990). The authors are aware of the limitations of the screen; for example, children classified as being speech impaired may have been deaf or hard of hearing, learning or neurologically impaired without gross signs, but further information was unavailable to unequivocally classify these children into other groups. Therefore, it was decided to create a speech-impairment group rather than to risk an incorrect classification.

\section{Socio-economic status}

No significant differences were identified by $t$ tests with respect to family background, housing and possessions. A descriptive summary of the study population is presented in Table 2. In summary, this was a poor population where most income was reliant on daily wage earnings. The literacy figures were lower than the national average shown in the 1991 census data for India (Indian Census Data, 1991).

\section{Nutritional status}

Food patterns. Information on food patterns was collected from 378 children. The common foods consumed daily were: chapatis (Indian bread) (61\%); dhal (pulses) $(65.6 \%)$; rice $(53.9 \%)$; vegetables $(50 \%)$. While this information indicates that the foods are accessible to the children, it does not indicate anything about the quantity or quality actually consumed. There were no significant differences between the children with disabilities and the siblings, thus suggesting that there was no preferential treatment within the same households with regard to food given.

The remaining foods in the questionnaire were less frequently eaten. The percentage of the population who rarely

Table 1. Children recruited for the study

\begin{tabular}{|c|c|c|c|c|c|c|c|c|c|}
\hline & \multicolumn{3}{|c|}{ Disabled } & \multicolumn{3}{|c|}{ Siblings* } & \multicolumn{3}{|c|}{ Neighbours $†$} \\
\hline & Total & Male & Female & Total & Male & Female & Total & Male & Female \\
\hline Total no. of children & 141 & 69 & 72 & 122 & 60 & 62 & 162 & 83 & 79 \\
\hline \multicolumn{10}{|c|}{ No. of children with impairments } \\
\hline Neurological impairments & 55 & 28 & 27 & & & & & & \\
\hline Motor impairments & 28 & 14 & 14 & & & & & & \\
\hline Speech impairments & 23 & 8 & 15 & & & & & & \\
\hline Sensory impairments & 17 & 6 & 11 & & & & & & \\
\hline Learning impairments & 14 & 9 & 5 & & & & & & \\
\hline Epilepsy & 4 & 3 & 1 & & & & & & \\
\hline \multicolumn{10}{|l|}{ Age (months) } \\
\hline Mean & 54 & & & 55 & & & 52 & & \\
\hline SD & 20 & & & 27 & & & 17 & & \\
\hline
\end{tabular}

* Nineteen children with disabilities did not have appropriately aged siblings.

†For matched controls, 141 neighbours were recruited. Only anthropometry and haemoglobin data were collected on the remaining neighbour children because their families wished to participate in the study. 
Table 2. A descriptive summary of the socio-economic status of the study population (282 families)

Study population description

Family background

Length of time living in Dharavi

Place of origin

Religion

Parental information

Mean age of parents

Literacy level

Paternal employment

Maternal employment

Primary carer

Household information

Family structure

Type of housing

Possessions owned
$71 \%$ of families had lived in the Dharavi slum for less than 10 years

The three main states of origin were: Uttar Pradesh (34\%), Maharashtra (32\%), Tamil Nadu (12\%)

Hinduism (63\%), Islam (27\%), Christianity (7\%), Buddhism (3\%)

Mother 28 (SD 5) years, father 33 (SD 5) years

Mother (32\%), father (50\%)

Unskilled (daily wage labourer) (55\%), semi-skilled (27\%), skilled (13\%), unemployed (5\%)

$18 \%$ worked outside of the home and others conducted some form of economic activity

from within the home

Mother (93\%), grandmother (3\%), sister (2\%), other (2\%)

Nuclear (56\%), extended (16\%), joint (28\%)

Permanent Structure Pucca $(39 \%)$, semi-permanent structure (14\%), temporary structure Kuccha $(47 \%)$ Bed $(44 \%)$, chair $(29 \%)$, light $(63 \%)$, fan $(57 \%)$, TV $(50 \%)$, stored food $(25 \%)$ or never consumed these foods were: vegetable water $(100 \%)$; sweet water $(97.9 \%)$; rice water $(99.2 \%)$; coconut water $(98.9 \%)$; fruit juice $(98.4 \%)$; dairy products $(98.1 \%)$; fruit $(80.3 \%)$; bread $(78.4 \%)$; eggs $(70.4 \%)$; milk $(72.3 \%)$; fish $(53.9 \%)$.

Comparing households with and without a disabled child, significant differences were identified in the mean frequency intake of meat. Meat was consumed significantly more $(P<0.05)$ frequently than 'rarely or never' among children in households without a disabled child compared with children in households with a disability. The data indicate that twenty-eight children with a disability, twenty-four sibling control children and forty-three neighbour control children consumed this expensive food once weekly.

Anthropometry. Table 3 summarises the anthropometric results for the disabled and non-disabled subjects.
All groups had low wt/age and ht/age data compared with the international reference standards (CDC, USA), and the values for the children with disabilities were significantly lower $(P<0.05)$ than for either siblings or neighbours. $\mathrm{Wt} / \mathrm{ht}$ data were also poor in all three groups and the values for the children with disabilities were significantly lower $(P<0 \cdot 05)$ compared with siblings, but not neighbour children. MUAC values were near-normal, with the highest values seen among the sibling group. Triceps skinfolds was significantly lower $(P<0.05)$ among the children with disabilities compared with neighbour children; however, no differences between the groups were observed for subscapular skinfolds. There were no significant differences between the two control groups.

The prevalence of moderate to severe malnutrition $(<-2 Z$ scores) was significantly greater among the children with disabilities compared with the non-disabled

Table 3. Anthropometry results of the case-control groups* (Mean values and standard deviations)

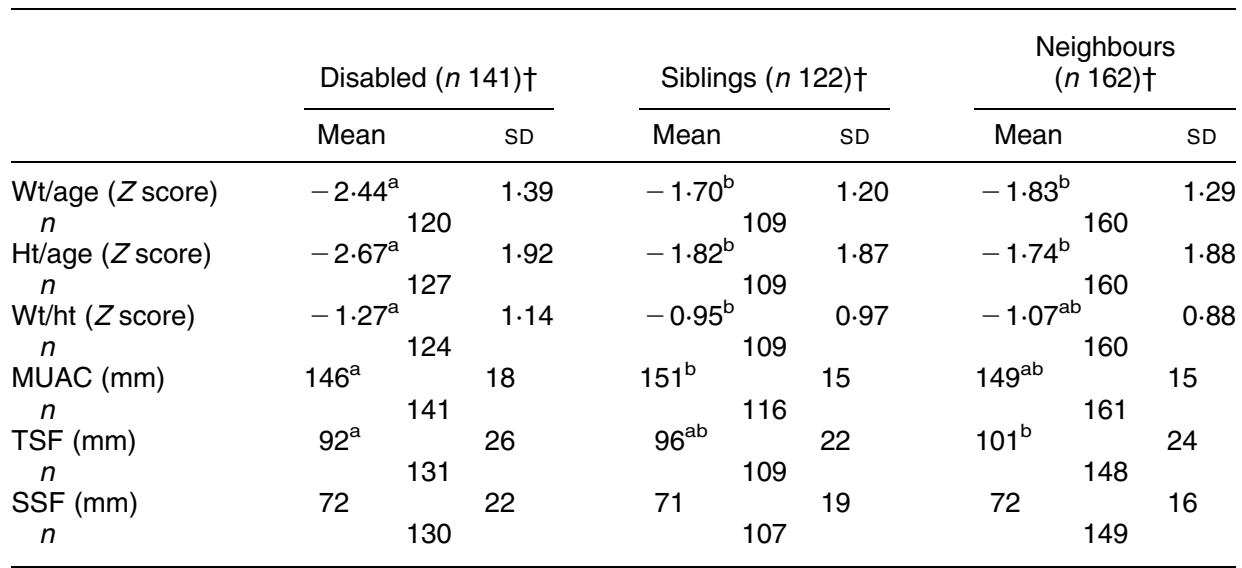

$\mathrm{Wt} /$ age, weight for age; Ht/age, height for age; Wt/ht, weight for height; MUAC, mid-upper arm circumference; TSF, triceps skinfold; SSF, subscapular skinfold.

${ }^{a, b}$ Mean values within a row with unlike superscript letters were significantly different $(P<0.05)$ by Duncan's multiple range test.

${ }^{*}$ For details of subjects and procedures see Tables 1 and 2 and p. 1098.

$\dagger$ In some cases it was not possible to take an accurate measurement, or the mother or child refused the taking of the measurement. Sibling children were most variable either because they were not available for the measurement to be taken or where the sibling nearest in age was not in the age range specified for the study. 


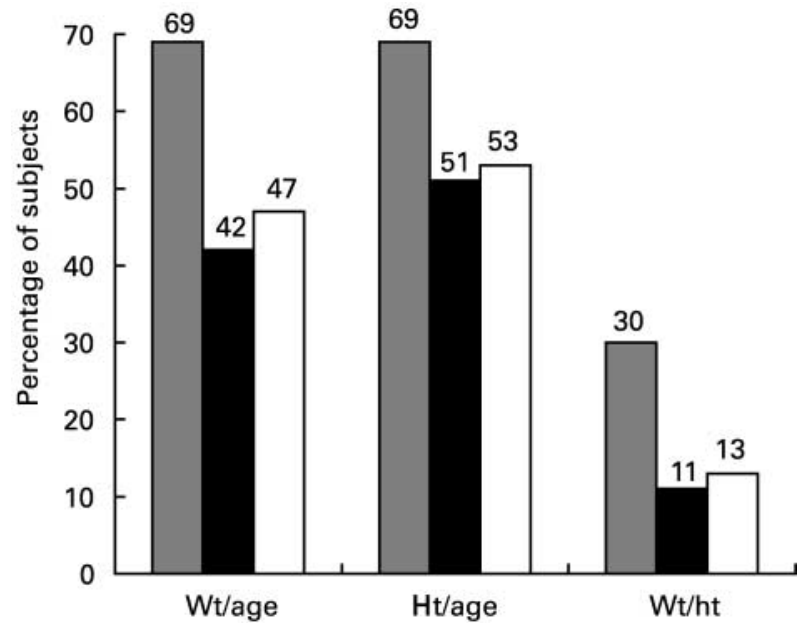

Fig. 1. The prevalence of moderate to severe malnutrition $(<-2 Z$ scores) in disabled children $(\square)$, siblings of the disabled children ( $\square$ ) and in neighbouring children ( $\square$ ). Wt/age, weight for age; Ht/age, height for age; $\mathrm{Wt} / \mathrm{ht}$, weight for height.

controls in wt/age $(P<0.001)$, ht/age $(P<0.001)$ and wt/ht $(P<0 \cdot 05)$ (Fig. 1).

Micronutrients and acute-phase proteins. The children with disabilities had significantly lower $(P<0.05)$ mean haemoglobin levels (92 (SD 23) g/l; $n$ 134) compared with siblings (102 (SD 18) g/l; $n$ 103) and neighbours (99 (SD 18) g/l; $n$ 153). The prevalence of anaemia was greater among the children with disability $(78 \%)$ compared with siblings $(63 \%)$ and neighbours $(74 \%)$. The proportion of the children with disability with a haemoglobin level below $90 \mathrm{~g} / \mathrm{l}$ was $45 \%$, which was nearly twice that of siblings $(23 \%)$ and neighbours $(24 \%)$. Serum micronutrient values did not differ significantly among the groups (Table 4). Of the total study population measured there was a $35 \%$ prevalence rate of both vitamin $\mathrm{A}$ and D deficiency. The only significant difference $(P=0 \cdot 05)$ identified was when the mean vitamin $D$ value was compared of the children with neurological impairment (19.7 (SD 15.8) $\mathrm{nM})$ with their matched sibling (31.4 (SD 27.8) nM) and neighbour (23.3 (SD 15.4) nM) controls.

Correlations among micronutrients and acute-phase proteins were investigated. No correlations were found

Table 4. Serum ferritin, vitamin $A$, vitamin $D$ and haemoglobin results for the subjects*

(Mean values and standard deviations)

\begin{tabular}{|c|c|c|c|c|c|c|}
\hline & \multicolumn{2}{|c|}{ Disabled } & \multicolumn{2}{|c|}{ Sibling } & \multicolumn{2}{|c|}{ Neighbour } \\
\hline & Mean & SD & Mean & SD & Mean & SD \\
\hline $\begin{array}{l}\text { Ferritin }(\mu g / l) \\
n\end{array}$ & $\begin{array}{r}48 \cdot 2 \\
5\end{array}$ & $27 \cdot 6$ & \multicolumn{2}{|c|}{41} & $\begin{array}{r}52 \cdot 4 \\
5\end{array}$ & $26 \cdot 8$ \\
\hline $\begin{array}{l}\text { Vitamin D (nM) } \\
n\end{array}$ & \multicolumn{2}{|c|}{43} & \multicolumn{2}{|c|}{29} & \multicolumn{2}{|c|}{41} \\
\hline \multicolumn{7}{|l|}{ Vitamin A ( $\mu \mathrm{M})$} \\
\hline Geometric mean & \multicolumn{2}{|c|}{0.8} & \multicolumn{2}{|c|}{0.7} & \multicolumn{2}{|c|}{0.7} \\
\hline $\begin{array}{l}95 \% \mathrm{Cl} \\
n\end{array}$ & \multicolumn{2}{|c|}{54} & \multicolumn{2}{|c|}{33} & \multicolumn{2}{|c|}{49} \\
\hline $\begin{array}{l}\text { Haemoglobin }(g / l) \\
\quad n\end{array}$ & $\begin{array}{r}92 \cdot 0 \\
15\end{array}$ & $23 \cdot 0$ & $\begin{array}{r}102 \cdot 0 \\
10\end{array}$ & $3^{18 \cdot 0}$ & $99 \cdot 0$ & $3^{18 \cdot 0}$ \\
\hline
\end{tabular}

${ }^{*}$ For details of subjects and procedures, see Tables 1 and 2 and p. 1098. between the haemoglobin and ferritin data. A significant negative association was identified between log-transformed vitamin A and log-transformed CRP $(P<0.001, r$ $-0.321 ; n$ 117), and between log-transformed vitamin A and ferritin $(P<0.001, r-0 \cdot 305 ; n$ 136) for all subjects. No significant differences between the groups could be identified in relation to the geometric means of acutephase proteins. Analysis of the acute-phase proteins could not account for the nutritional status differences between the disabled and non-disabled children.

\section{Feeding difficulties}

The risk of inadequate nutritional status could not be determined by exploring individual impairment classifications because each impairment group comprised many different health conditions and varying severity. Analysis by limitations in feeding (at the functional and activity level) was considered more appropriate.

Of the children with disabilities, thirty-nine were classified as having severe feeding difficulties and 101 were classified as having minor or no feeding difficulties. The risk of malnutrition for the disabled children with feeding difficulties relative to the disabled children having no or minor feeding difficulties was analysed (Table 5).

The children with disabilities were 1.1 to 2.4 times more likely to have moderate to severe underweight, stunting, and wasting if a feeding difficulty was present than if no feeding difficulty was present. The children with feeding difficulties were 1.8 times more likely to have a MUAC indicative of malnutrition $(<125 \mathrm{~mm})$ (Gibson, 1990) than if no feeding difficulties were present. The children with disabilities were 2.0 times more likely to have ferritin levels indicative of $\mathrm{Fe}$ deficiency if a feeding difficulty was present than those with no feeding difficulties. The children with disabilities were 1.8 times more likely to have deficient vitamin D levels if a feeding difficulty was present than if no feeding difficulties were present.

Of the disabled subjects followed up, thirty-nine were described as independent feeders by the carer and

Table 5. Relative risks (RR) of malnutrition of disabled children with feeding difficulties compared with disabled children with minor or no feeding difficulties $†$

(Relative risks and $95 \%$ confidence intervals)

\begin{tabular}{|c|c|c|c|}
\hline \multirow[b]{2}{*}{ Nutritional indices } & \multicolumn{3}{|c|}{ Feeding difficulties ( $n$ 39) } \\
\hline & $\mathrm{RR}$ & $95 \% \mathrm{Cl}$ & $n$ \\
\hline Wt/age (<-2 Z score) & $1 \cdot 1^{*}$ & $1 \cdot 08,1 \cdot 20$ & 38 \\
\hline Ht/age ( $<-2 Z$ score) & $1 \cdot 3^{*}$ & $1.19,1.43$ & 38 \\
\hline Wt/ht (<-2Z score) & $2 \cdot 4^{*}$ & $1 \cdot 78,3 \cdot 23$ & 36 \\
\hline MUAC $(<125 \mathrm{~mm})$ & $1 \cdot 8^{\star}$ & $1.57,2.06$ & 36 \\
\hline Haemoglobin $(<110 \mathrm{~g} / \mathrm{l})$ & $1 \cdot 0$ & $1.00,1.00$ & 35 \\
\hline Ferritin $(<10 \mathrm{~g} / \mathrm{l})$ & $2 \cdot 0^{\star}$ & $1 \cdot 61,2.48$ & 14 \\
\hline Vitamin A $(<0.7 \mu \mathrm{M})$ & $1 \cdot 0$ & $1.00,1.00$ & 12 \\
\hline Vitamin D (<30 NM) & $1 \cdot 8^{\star}$ & $1 \cdot 12,3 \cdot 20$ & 17 \\
\hline
\end{tabular}

$\mathrm{Wt} /$ age, weight for age; Ht/age, height for age; Wt/ht, weight for height; MUAC, mid-upper arm circumference.

* RR of significantly more $(P<0.05)$ likely to be malnourished if child had a feeding difficulty than no or minor feeding difficulty.

†For details of subjects and procedures, see Tables 1 and 2 and p. 1098. 
thirty-nine required help with feeding. The key findings from the interviews were about: (1) the time taken to feed a child with disabilities; (2) perceptions about hunger; (3) feeding positions.

Time taken to feed a child with disabilities. A $100 \mathrm{~mm}$ Likert scale was used for the carer to describe the length of time taken for a disabled subject to complete a meal. Children were classified as taking a long time to complete a meal (marked between 10 and $40 \mathrm{~mm}$ ), an expected normal time to complete a meal (marked between 50 and $60 \mathrm{~mm}$ ) or taking a short time to complete a meal (marked between 70 and $100 \mathrm{~mm}$ ). Of the subjects, $67 \%$ took a long time to complete a meal and $18 \%$ took a short time to complete a meal compared with siblings. The distribution of cases taking longer and shorter times than the expected normal times to complete a meal were significant $\left(\chi^{2} 38 \cdot 6 ; P<0 \cdot 001\right)$.

For the thirty-nine subjects that required help with feeding, $62 \%(n 24)$ carers felt they did not have sufficient time for feeding. The regular feeding responsibility was primarily the mother ( $n$ 19) and then grandmother $(n 4)$. However, one-third ( $n$ 13) of dependent feeders did not have a regular feeder and were fed by any available family member. The majority of the children with disabilities ate at the same time as their siblings; however, $21 \%$ of siblings ( $n$ 15) were also dependent feeders, thus limiting available time for individual attention of the disabled child.

Perceptions about hunger. The detailed interview questionnaire asked whether both the disabled child and the sibling had good, moderate or poor appetites and thirst. The subjects with disabilities $(55 \%)$ were significantly more likely than siblings $(8 \%)$ to be described as having a moderate to poor appetite $\left(\chi^{2} 56 \cdot 6 ; P<0.001\right)$. The children with disabilities $(54 \%)$ were also significantly more likely than siblings $(8 \%)$ to be described as having a moderate to poor thirst $\left(\chi^{2} 54 \cdot 6 ; P<0.001\right)$.

Feeding positions. Feeding position is particularly important for those children who require help with feeding in order to prevent choking and gagging. A good position also improves the swallowing process (Larnert \& Ekberg, 1995). A photograph was taken with each subject in a typical feeding position ( $n$ 65). Researcher observations of the photographs were used to judge whether intervention was necessary for the improvement of the feeding position. Of the photographs, $15 \%(n$ 10) showed areas where specific feasible intervention was possible. These children were either fed lying down or without necessary support. The information provided an important input for the development of future interventions. The researcher A. Y. visited each household on several occasions before the photograph was taken in order for the researcher to have some familiarity with the normal feeding practices and positions for the individual child.

\section{Discussion}

Different aspects of nutrition were investigated in the present exploratory study. Mallory et al. (1993) suggest that disabled children living in poverty may be at risk of inadequate nutritional status due to financial constraints or social beliefs. The findings of the food-patterns survey indicated that there was no preferential treatment between the disabled child and siblings in this age group regarding food given. King \& Burgess (1993) discussed that in some communities a disabled child may be thought of as sick and fed inadequately because of the fear of making the illness worse. Some families of children with disabilities in Dharavi commented that the process of eating was difficult and painful if the child had a disability and felt that improved feeding would take place once the child was 'stronger' (Yousafzai et al. 2003b). Therefore, further information about the quantity and the quality of the food actually consumed by the children would be useful to explore differences in intake that may impact on nutritional status.

The only significant difference in relation to food patterns was that the more expensive food group of meat was consumed significantly more $(P<0.05)$ frequently in households of the neighbour children, but there are no differences in the family background data to indicate why this may occur (Table 2).

The null hypothesis for the present investigation was that the nutritional status of children with disabilities living in an Indian slum was not different from that of children without disability based on the assumption of the widespread malnutrition among the general population in a lowincome community. The prevalence of moderate to severe malnutrition by wt/age (the expected most reliable anthropometric indicator of nutritional status) shows more than $40 \%$ of malnutrition for all groups (Fig. 1). This is similar to the 1998-1999 National Family Health Survey (2000) data for India that indicate a prevalence of $47 \%$ underweight among children under 6-36 months of age.

No significant differences were observed between sibling and neighbour children, suggesting that the sibling children were not likely to be nutritionally disadvantaged within households. The children with disabilities had significantly lower mean wt/age, ht/age, wt/ht, triceps skinfolds and haemoglobin, and a higher prevalence of moderate to severe malnutrition compared with the controls. The anthropometry results of the present study were in agreement with a Nigerian study that found significantly lower mean values for the mixed disabled cases $(n$ 112 ) in wt/age and ht/age compared with the controls (siblings $n 87$ and neighbours $n$ 112) (Tompsett et al. 1999).

Tompsett et al. (1999) found that mean haemoglobin levels were significantly higher $(P<0.05)$ for the disabled and sibling subjects $(107 \mathrm{~g} / \mathrm{l})$ compared with the controls $(101 \mathrm{~g} / \mathrm{l})$. In the present study, the mean haemoglobin values for all subjects were lower for the Indian population compared with the Nigerian population. Surveys conducted in India between 1998 and 1999 indicated the prevalence of anaemia to be $74 \%$ among children under 6-36 months of age (National Family Health Survey, 2000), with a higher prevalence when associated with poorer maternal literacy levels as is to be observed in an area such as Dharavi. In the present study the prevalence of anaemia was $78 \%$ for the children with disability, $63 \%$ for the siblings and $74 \%$ for the neighbour children; therefore, the results may be expected for an Indian population.

Low energy intake among children with disabilities has been reported in studies conducted in the West; however, 
in low-income communities consideration of micronutrient deficiencies is also important (Sullivan et al. 2002). The authors were unable to find previous disability and nutrition studies in poorly resourced communities that have investigated micronutrient status. No significant differences could be identified between the groups in the present study, except for significantly lower $(P<0.05)$ vitamin D levels among the children with neurological impairment compared with the control group. It can be speculated that this may have been due to the severity of the disability in this group resulting in very little or no time spent outdoors in sunlight. Of the total study population measured, $35 \%$ had vitamin D levels below $30 \mathrm{~nm}$ indicative of deficiency, which may lead to an individual being more susceptible to impairments caused by osteoporosis or rickets. Agarwal et al. (2002) found mean vitamin D levels in 2-year-old children living in highly polluted areas of Delhi, India to be significantly lower than in less polluted areas. Children may also cover up more when in the sun because of the cultural preferences for a fairer skin complexion in some parts of India (Singh et al. 1992).

Of the total study population measured, $35 \%$ had vitamin A levels below $7 \mu \mathrm{M}$, indicative of deficiency. The National Family Health Survey (2000) reports that the vitamin A coverage in India in 1998-1999 was $29.7 \%$ nationally, with better coverage in urban areas. Dharavi is located in Maharashtra state, which has the second highest reported vitamin A coverage level of $64.7 \%$ (National Family Health Survey, 2000). Further work exploring micronutrient status, acute-phase proteins and morbidity among children with disability will be useful.

The impairment groups comprised different health conditions and varying severity; therefore, analysis by impairment group was less useful in understanding the nutritional problems in the present study population. The data on feeding difficulties leading to a reduced intake and/or absorption of nutrients provided one possible factor that may explain some of the differences in nutritional status, which is in agreement with previous studies conducted in higher-income communities (Thommessen et al. 1991). The identification of major feeding difficulties was based on parental responses to specific questions about feeding independence, vomiting frequency and degree of chewing difficulty. The subjects with feeding difficulties were significantly more likely $(P<0.05)$ to be at risk of poorer wt/age, ht/age, wt/ht, MUAC, ferritin and vitamin D status than those subjects with no feeding difficulties.

Feeding problems have been observed in 40-90\% children with cerebral palsy; particularly severe problems exist for quadriplegic cases (Reilly \& Skuse, 1994; Trier \& Thomas, 1998). Many studies have focused primarily on feeding problems as a consequence of oral-motor difficulties (Krick \& van Duyn, 1984). Stallings et al. (1993) identified in a clinical study that children with hemiplegic cerebral palsy were significantly more likely $(P<0.01)$ than children with diplegic cerebral palsy to have oralmotor difficulties that can impact on food intake. Undernutrition in children with cerebral palsy has been documented in a number of clinical studies (Shapiro et al. 1986; Stallings et al. 1993; Hals et al. 1996). In a communitybased study in the Philippines, Socrates et al. (2000) assessed children with cerebral palsy for impaired selffeeding that indicated that wt/age was significantly lower $(P<0.05)$ for disabled subjects with impaired self-feeding than those with moderate or no self-feeding problems.

Generally in poorly resourced communities, the assessments of feeding difficulties are likely to be made by community health workers with little specialist training, unlike health therapists. Parental reporting may provide a useful means of identifying children with feeding problems that require attention, particularly because professional observation of feeding difficulties at a single time point may overlook some problems that parents deal with on a daily basis. The accuracy of maternal responses to child illness has been recorded in the literature (Rousham et al. 1998). Although parents may over-report feeding problems to gain attention for a disabled child, particularly in an otherwise poorly resourced area, it is potentially one method of finding children with disabilities who are at risk of malnutrition and nutrition-related problems and warrants further research.

Given the additional problems experienced during mealtimes, it may be speculated that differences in intake occur for children with disabilities compared with controls. For example, the disabled child may not be fed to satiety because of insufficient time for feeding. A perceived lack of appetite and thirst for the disabled children compared with sibling controls by parental response $(P<0 \cdot 001)$ was identified in the present study, which is in agreement with previous qualitative research (Yousafzai et al. $2003 b$ ). Thommessen et al. (1989) found all ten cases studied with congenital severe deaf-blindness were more likely to frequently refuse food than non-disabled children of a similar age. Few other studies have investigated the lack (or perceived lack) of interest in food by children with disabilities.

Slightly more disabled children than non-disabled children took an abnormal amount of time to complete a meal $(P<0 \cdot 001)$. Of the parents of dependent feeders, $62 \%$ said they did not feel they had sufficient time to feed their child. Studies of children with cerebral palsy have also identified that the time taken to complete a meal is frequently much longer than for non-disabled children (Johnson \& Deitz, 1985; Gisel \& Patrick, 1988; Reilly \& Skuse, 1992). The most important consequence is the experience of carer stress affecting feeding management (Reilly \& Skuse, 1992). In poor communities such as Dharavi, finding free time for additional care activities is complicated by other competing priorities for parents (Yousafzai et al. 2003b).

\section{Conclusion}

Attention toward the nutritional status of all subjects in the Dharavi study area is needed. Among children with disabilities, feeding difficulties were identified as a risk factor for vulnerability to inadequate nutritional status in six of the eight measured areas. Parental responses about feeding difficulties were useful in identifying feeding problems. From a programme perspective, community health workers in poorly resourced communities could be trained in using a simple screen to identify children who need additional 
support in developing feeding skills, therefore contributing to reducing further disabling consequences. When the 'gap' is considered in needs and the provision of rehabilitation services (Helander, 1998), addressing nutrition for children with disabilities could be incorporated into general community nutrition programmes. Feeding will be influenced by socio-cultural factors regarding nutrition, childcare and disability and these factors must be examined more closely in future work.

\section{Acknowledgements}

The study was conducted in collaboration with the Spastics Society of India. The authors are very grateful to all the families who willingly participated in the study. The authors would like to thank the field assistants who all enthusiastically supported the data-collection work. Many thanks are given to Dr Neeta Jain for the provision of the micronutrient supplements. The hard work of the staff at the Mumbai Diagnostics Centre and the Family Diagnostics Clinic for the blood collections is appreciated. Further thanks are given to Abby Woodfin for running all the ELISA assays. The study was funded by the Department for International Development (DFID), UK. Their support is gratefully acknowledged. This work was undertaken in collaboration with the Great Ormond Street Hospital for Children NHS Trust which receives a proportion of its funding from the NHS Executive.

\section{References}

Agarwal KS, Mughal MZ, Upadhyay P, Berry JL, Mawer EB \& Puliyel JM (2002) The impact of atmospheric pollution on vitamin D status of two year olds in Delhi, India. Arch Dis Child 87, 111-113.

American Dietetic Association (1992) Position of the American Dietetic Association - nutrition in comprehensive programme planning for persons with developmental disabilities. $\mathrm{J} \mathrm{Am}$ Diet Assoc 92, 613-615.

Beesley R, Filteau SM, Tomkins A, et al. (2000) Impact of acute malaria on plasma concentrations of transferring receptors. Trans $R$ Soc Trop Med Hyg 94, 295-298.

Bhandari N, Bahl R, Sazawal S \& Bhan K (1997) Breast feeding status alters the effect of vitamin A treatment during acute phase diarrhoea in children. $J$ Nutr 127, 59-63.

Coleridge P (1993) Disability, Liberation and Development. Oxford: Oxfam Publications.

Crean JTG, Ling SC, Pearson DJ, Shaw SN, Stewart RJ \& Wilson JH (1987) Dharavi Project 1985: an investigation into patterns of infant feeding and malnutrition in the urban slum of Dharavi in Bombay. J Trop Paediatr 33, Suppl. 2, 2-30.

Durkin MS, Davidson LL, Desai P, et al. (1994) Validity of the ten questions screen for childhood disability - results from population-based studies in Bangladesh, Jamaica, and Pakistan. Epidemiology 5, 283-289.

Durkin MS, Wang W, Shrout PE, et al. (1995) Evaluating a ten questions screen for childhood disability - reliability and internal structure in different cultures. J Clin Epidemiol 48, 657-666.

Filteau SM, Lietz G, Mulokozi G, Billota S, Henry CJ \& Tomkins AM (1999) Milk cytokines and sub-clinical breast inflammation in Tanzanian women - effects of dietary red palm oil or sunflower oil supplementation. Immunology $\mathbf{9 7}$, 596-600.
Filteau SM, Morris SA, Abbot RR, et al. (1995) Influence of morbidity on serum retinol of children in a community-based study in Northern Ghana. Am J Clin Nutr 58, 192-197.

Fung EB, Samson-Fang L, Stallings VA, et al. (2002) Feeding dysfunction is associated with poor growth and health status in children with cerebral palsy. J Am Diet Assoc 102, 361-373.

Gibson RS (1990) Principles of Nutritional Assessment. New York: Oxford University Press.

Gisel EG \& Patrick J (1988) Identification of children with cerebral palsy unable to maintain a normal nutritional state. Lancet i, 283-286.

Hals J, Ek J, Svalastog AG \& Nilsen H (1996) Studies on nutrition in severely neurologically disabled children in an institution. Acta Paediatr 85, 1469-1475.

Harris AD, Jones LA, Heatley RV, Newcomb RG \& Rhodes J (1984) Precision of anthropometric measurements - the value of mid-arm circumference. Clin Nutr 2, 193-196.

Helander E (1998) Prejudice and Dignity - An Introduction to Community Based Rehabilitation, 2nd ed., New York: UNDP.

Indian Census Data (1991) Census of India 1991. http://www. censusindia.net

Johnson CB \& Deitz JC (1985) Time use of mothers with preschool children: a pilot study. Am J Occup Ther 39, 578-583.

King FS \& Burgess A (1993) Nutrition for Developing Countries. Oxford: Oxford Medical Publications.

Kow F, Geissler C \& Balasubramaniam E (1991) Are international anthropometric standards appropriate for developing countries? J Trop Pediatr 37, 37-44.

Krick J \& van Duyn M (1984) The relationship between oralmotor involvement and growth - a pilot study in a paediatric population with cerebral palsy. $J$ Am Diet Assoc 84, 555-559.

Larnert G \& Ekberg O (1995) Positioning improves the oral and pharyngeal swallowing function in children with cerebral palsy. Acta Paediatr 84, 689-692.

Lawson M, Thomas M \& Hardman A (1999) Dietary and lifestyle factors affecting plasma vitamin D levels in Asian children living in England. Eur J Clin Nutr 53, 268-272.

Mallory BL, Nichols RW, Charlton JI \& Marfo K (1993) Traditional and Changing Views of Disability in Developing Societies: Causes, Consequences, Cautions. Durham: World Rehabilitation Fund - The International Exchange of Experts and Information in Rehabilitation, The University of New Hampshire, NC, USA.

National Family Health Survey (2000) National Family Health Survey, India 1998-1999. http://www.nfhsindia.org

Pai M, Alur M, Wirz S, Filteau S, Pagedar S \& Yousafzai A (2001) A pilot study of the nutritional status of disabled and non-disabled children living in Dharavi, Mumbai. J Indian Pediatr 38, 60-65.

Ramakrishnan U, Latham MC, Abel R \& Frongilo EA (1995) Vitamin A supplementation and morbidity among pre-school children in South India. Am J Clin Nutr 61, 1295-1303.

Reddihough DS, Baikie G \& Walstab JE (2001) Cerebral Palsy in Victoria, Australia: Mortality and causes of death. J Paediatr Child Health 37, 183-186.

Reilly S \& Skuse D (1994) The prevalence of feeding problems in pre-school children with cerebral palsy. Dev Med Child Neurol 36, Suppl., 5.

Reilly S \& Skuse D (1992) Characteristics and management of feeding problems of young children with cerebral palsy. Dev Med Child Neurol 34, 379-388.

Richardson N (1988) Feeding Problems, Emotional and Behavioural Problems in Young Children - A Multi-disciplinary Approach. Windsor, UK: NFER.

Sullivan PB \& Rosenbloom L (1996) Feeding the Disabled Child, Clinics in Developmental Medicine. London and Cambridge, UK: MacKeith Press/Cambridge University Press. 
Rousham EK, Northrop-Clewes CA \& Lunn PG (1998) Maternal reports of child illness and the biochemical status of the child: the use of morbidity interviews in rural Bangladesh. $\mathrm{Br} J$ Nutr 80, 451-456.

Shapiro BK, Green P, Krick J, Allen D \& Capute AJ (1986) Growth of severely impaired children - neurological factors versus nutritional factors. Dev Med Child Neurol 28, 729-733.

Shaw BNJ (1996) The respiratory consequences of neurological deficit. In Feeding the Disabled Child, Clinics in Developmental Medicine, pp. 40-46 [PB Sullivan and L Rosenbloom, editors]. London and Cambridge, UK: MacKeith Press/Cambridge University Press.

Singh J, Marya RK \& Sharma A (1992) Screening of rickets in a Haryana town. J Indian Pediatr 29, 226-228.

Singhal S, Goyle A \& Gupta R (1998) Quantitative food frequency questionnaire and assessment of dietary intake. Natl Med J India 11, 268-275.

Socrates C, Grantham-McGregor SM, Harknett SG \& Seal AJ (2000) Poor nutrition is a serious problem in children with cerebral palsy in Palwan, the Philippines. Int $J$ Rehabil Res 23, 177-184.

Staiano A, Cucchiara S, Del Giudice E, Andreotti MR \& Minella R (1991) Disorders of oesophageal motilityin children with psychomotor retardation and gastro-oesophageal reflux. Eur J Pediatr 150, 638-641.

Staiano A \& Del Giudice E (1994) Colonic transit and anorectal manometry in children with severe brain damage. Pediatrics 94, 169-173.

Stallings VA, Charney EB, Davies JC \& Cronk CE (1993) Nutritional status and growth of children with diplegic or hemiplegic cerebral palsy. Dev Med Child Neurol 35, 997-1006.

Stallings VA, Zemal BS, Davies JC, Cronk CE \& Charney EB (1996) Energy expenditure of children and adolescents with severe disabilities: a cerebral palsy model. Am J Clin Nutr 64, 627-634.

Sullivan PB, Juszack E, Lambert BR, Rose M, Ford-Adams ME \& Johnson A (2002) Impact of feeding problems on nutritional intake and growth: Oxford feeding study II. Dev Med Child Neurol 44, 461-467.

Suzuki M, Saitoh S, Tasaki Y, Shimomura Y, Makishima R \& Hosoya N (1991) Nutritional status and daily physical activity of handicapped students in Tokyo metropolitan schools for deaf, blind, mentally retarded, and physically handicapped individuals. Am J Clin Nutr 54, 1101-1111.
Thomas AP, Bax MCO \& Smyth DPL (1989) The Health and Social Needs of Young Adults with Physical Disabilities, Clinics in Developmental Medicine no. 106. London: MacKeith Press.

Thommessen M, Kase BF, Riis G \& Heiberg A (1991) The impact of feeding problems on growth and energy intake in children with cerebral palsy. Eur J Clin Health 45, 479-487.

Thommessen M, Trygg K, Riis G \& Kase BF (1989) Nutrition and growth retardation in 10 children with congenital deafblindness. J Am Diet Assoc 89, 69-73.

Tietz NW (1995) Clinical Guide to Laboratory Tests, 3rd ed., Philadelphia, PA: WB Saunders Company.

Tompsett J, Yousafzai AK \& Filteau SM (1999) The nutritional status of disabled children in Nigeria - a cross-sectional survey. Eur J Clin Nutr 53, 915-919.

Trier H \& Thomas AG (1998) Feeding the disabled child. Nutrition 10, 801-805.

Turmusani M, Vreede A \& Wirz SL (2002) Some ethical issues in community-based rehabilitation initiatives in developing countries. Disabil Rehabil 24, 558-564.

United Nations (1986) How to Weigh and Measure Children Assessing the Nutritional Status of Young Children in Household Surveys. New York: UN Department of Technical Co-operation for Development and Statistical Office.

Verrall TC, Berenbaum S, Chad KE, et al. (2000) Children with cerebral palsy: caregivers' nutrition knowledge, attitudes and beliefs. Can J Diet Pract Res 61, 128-134.

Willig TN, Carlier L, Legrand M, et al. (1993) Nutritional assessment in Duchenne muscular dystrophy. Dev Med Child Neurol 35, 1074-1082.

World Health Organisation (1992) The Prevalence of Anaemia in Women: a tabulation of available information. Geneva: WHO.

Yousafzai AK, Filteau S, Wirz S \& Cole TJ (2003a) The use of armspan, arm length and tibia length to assess nutritional status in children with physical impairments in Dharavi, Mumbai, India. Eur J Clin Nutr (In the Press).

Yousafzai AK, Pagedar S, Wirz S \& Filteau S (2003b) Beliefs about feeding practices and nutrition for children with disabilities among families in Dharavi, Mumbai. Int J Rehabil Res 26, 33-41.

Zamen SS, Khan NA, Islam S, et al. (1990) Validity of the "ten questions" for screening serious childhood disability - results from urban Bangladesh. Int J Epidemiol 19, 613-620. 